\title{
Prevalence and Characteristics of Anemia Associated with Thyroid Disorders in Non-pregnant Saudi Women during the Childbearing Age: A Cross-sectional Study
}

\author{
Bassem Refaat
}

Background: Little is known about the prevalence of thyroid disorders and their associated anemia in the Kingdom of Saudi Arabia. The aim of the current study was to measure the prevalence and types of thyroid disorders and their relationship with anemia frequency and types in non-pregnant Saudi females during the childbearing age.

Methods: Blood samples were collected from 600 non-pregnant females (between $\geq 18$ and $\leq 45$ years) with no history of thyroid dysfunction, chronic diseases, and/or anemia to measure serum thyroid stimulating hormone (TSH), free $\mathrm{T} 4$, erythrocyte indices, and iron parameters.

Results: Thyroid disorders were detected in 118 participants (19.6\%), and occult hypothyroidism was the most prevalent type (70/118) followed by overt hypothyroidism (38/118) and hyperthyroidism (10/118). Anemia was detected in 52 females with abnormal thyroid (44\%) and the prevalence was significantly higher $(p<0.05)$ compared to euthyroid (14.3\%). The red blood cell (RBC) count, hemoglobin, hematocrit value, serum iron, and serum ferritin were significantly lower in thyroid disorder compared to euthyroid group $(p<0.05)$. Erythrocyte indices correlated significantly with serum free T4, while iron parameters correlated with serum TSH $(p<0.05)$.

\section{At a Glance Commentary \\ Scientific background of the subject}

Thyroid disorders are associated with several complications including the development of anemia. We measured the frequency of thyroid disorders among 600 non-pregnant Saudi women during the childbearing age and, the prevalence of anemia were then compared between thyroid disorders and euthyroid group.

\section{What this study adds to the field}

Thyroid abnormalities appeared to be common in non-pregnant Saudi females in the kingdom and it was associated with pathological erythrocyte indices, iron parameters and anemia in $44 \%$ of cases. Further studies are needed to identify the underlying mechanism(s) and etiological factors contributing in the development of thyroiditis induced anemia.

Conclusion: Thyroid disorders are common in non-pregnant females in the Western province of Saudi Arabia, and they are associated with an increase in the prevalence of both anemia and iron deficiency. Further studies are needed to determine the underlying mechanism (s) contributing to the development of thyroiditis-induced anemia in the kingdom and the role of thyroid hormones in iron metabolism.

(Biomed J 2015;38:307-316)

\section{Key words: anemia, non-pregnant female, reproductive age, Saudi Arabia, thyroid}

$\mathrm{T}$ Thyroid hormones are essential for the normal development, differentiation, metabolic balance, and physiological function of virtually all tissues ${ }^{[1]}$ and thyroid function disorders are among the most common endocrine diseases. ${ }^{[2-5]}$ Thyroid disorders affect females more than males, especially during the reproductive age. ${ }^{[6-8]}$ The prevalence of thyroid disorders differs from one society to another and hypothyroidism is the most prevalent type with a reported frequency of $2-5 \%$ worldwide. ${ }^{[7,9]}$ Also, the prevalence of subclinical hypothyroidism is approximately $4-8.5 \%$ and it can increase

From the Laboratory Medicine Department, Faculty of Applied Medical Sciences, Umm Al-Qura University, Al Abdeyah, Makkah, KSA Received: Aug. 09, 2014; Accepted: Jan. 15, 2015

Correspondence to: Dr. Bassem Refaat, Laboratory Medicine Department, Faculty of Applied Medical Sciences, Umm Al-Qura University, Makkah, KSA. P.O. Box 7607, KSA. Tel: 966-541162707; Fax: 966-12-5270000 ext. 4242; E-mail: Bassem.refaat@yahoo.co.uk

DOI: $10.4103 / 2319-4170.151032$ 
to up to $20 \%$ in women aged 60 years or older. ${ }^{[6,7,10]}$ Alternatively, hyperthyroidism is less prevalent with a frequency ranging between 0.5 and $2 \%$ in women..$^{[1,3,10-15]}$

Thyroid disorders are associated with hematological abnormalities and anemia is the most prevalent disorder. ${ }^{[6,12,16-18]}$ Early reports have shown a decrease in the number of red blood cells (RBCs) in the peripheral blood of patients after thyroidectomy ${ }^{[19]}$ and anemia has been defined in $20-60 \%$ of the patients with hypothyroidism. ${ }^{[7,8,16]}$ Although early reports showed that Graves' disease is also associated with hematological disorders, ${ }^{[11,14,15]}$ anemia is not frequently observed in patients with hyperthyroidism, whereas erythrocytosis is common. ${ }^{[8,15,16]}$ Furthermore, it has been found that all hematological parameters return to normal when a euthyroid state is achieved. ${ }^{[14,20-23]}$

Females are more prone to the development of thyroid disorders and/or anemia, especially during the reproductive age and pregnancy. ${ }^{[2,3,6,7,12]}$ Little is known about the incidence of thyroid disorders and their associated types of anemia in Saudi Arabia. Therefore, the aim of the current study was to measure the prevalence and types of thyroid disorders and to study their relationship with anemia frequency and anemia types in non-pregnant females during the childbearing age.

\section{METHODS}

\section{Ethical approval}

Ethical approval was obtained from the University Review Ethics Committee before starting the study and all serum samples were collected after obtaining informed written consent from all the participants.

\section{Study design}

Five milliliters of blood sample was collected from 600 non-pregnant women (age range between 18 and 45 years) who were selected based on the inclusion and exclusion criteria [Table 1] during their routine check-up at the university medical center between January and December 2013. All participants filled a questionnaire regarding their medical history and the reason for attending the medical center. To be included in the study, the participants had to be healthy with no current or past history of acute illness within at least 3 months prior to recruitment, no past history of/current chronic medical condition, not using medication for significant clinical disease, and not taking iron or vitamin supplementation. The recruitment of participants was consecutive, and half of the blood sample $(2.5 \mathrm{ml})$ was collected in tubes containing ethylenediaminetetraacetic acid (EDTA) and the rest in plain tubes.

The participants were divided into two groups according to their thyroid profile results. Patients with normal thyroid profile served as the "control group" and their hematological results and iron parameters were compared with those obtained from the "thyroid disorder" group.

\section{Thyroid hormone measurements}

Whole blood samples $(2.5 \mathrm{ml})$ were collected through venepuncture, centrifuged at $3000 \mathrm{rpm}$ for $20 \mathrm{~min}$, and then the obtained serum samples were stored frozen at $-20^{\circ} \mathrm{C}$ until use. The quantitative measurement of thyroid stimulating hormone (TSH) and free thyroxin hormone (FT4) was done using electro-chemiluminescence immunoassay (ECLIA) on Cobas e411 (Roche Diagnostics International Ltd, Basel, Switzerland) according to the manufacturer protocol. The normal range, according to the manufacturer, for TSH and free T4 was $0.27-4.20 \mu \mathrm{IU} / \mathrm{ml}$ and $12-22 \mathrm{pmol} / \mathrm{l}$, respectively. The detection sensitivity was $0.005 \mu \mathrm{IU} / \mathrm{ml}$ for TSH and $0.3 \mathrm{pmol} / \mathrm{l}$ for FT4. The intra- and inter-assay coefficients of variations for FT4 were 1.7 and $3.9 \%$, respectively, and for TSH were 1.4 and $3.4 \%$, respectively. The diagnosis and classification of thyroid abnormalities were according to the guidelines of the National Academy of Clinical Biochemistry (NACB) for laboratory diagnosis and monitoring of thyroid diseases. ${ }^{[24]}$ Hypothyroidism was considered when TSH was $>4.5 \mu \mathrm{IU} / \mathrm{ml}$ and the level of FT4 defined the type as either primary $(\mathrm{FT} 4<12 \mathrm{pmol} / \mathrm{l})$ or subclinical (FT4 $\geq 12 \mathrm{pmol} / \mathrm{l}$ ). Hyperthyroidism was considered for TSH $<0.10 \mu \mathrm{IU} / \mathrm{ml}$ and FT4 $>22 \mathrm{pmol} / \mathrm{l}$.

Table 1: Principal inclusion and exclusion criteria

\begin{tabular}{ll}
\hline Principal inclusion criteria & Principal exclusion criteria \\
\hline Female participant & Male participant \\
Patient age $>18$ and $<45$ years & Patient age $<18$ or $>45$ years \\
Regular menstrual cycle and/or of proven fertility & Irregular menstrual cycle and/or infertility \\
Not on hormonal therapy and/or oral contraceptive pills & On hormonal therapy and/or oral contraceptive pills \\
No history of thyroid disorder & History or known current thyroid disorder \\
Not known to be anemic & Known to be anemic \\
Not taking vitamins and/or iron supplementation & Taking vitamins and/or iron supplementation \\
No history of autoimmune condition (e.g. type 1 DM, rheumatoid arthritis, etc.) & Autoimmune condition (e.g. type 1 DM, rheumatoid arthritis, etc.) \\
No concurrent chronic disease (e.g. renal, respiratory, cardiac, liver, type 2 & Concurrent chronic disease (e.g. renal, respiratory, cardiac, \\
DM and hypertension) & liver, type 2 DM, and hypertension) \\
\hline
\end{tabular}

Abbreviation: DM: Diabetes mellitus 


\section{Determination of hematological profile}

Whole blood samples $(2.5 \mathrm{ml})$ collected in EDTA containing tubes were processed on Sysmex XS 500 with five-parameter differential (Sysmex, Lincolnshire, IL, USA) for the measurement of hemoglobin concentrations, RBC count, packed cell volume (PCV), mean corpuscular volume (MCV), and mean corpuscular hemoglobin (MCH). Anemia was defined by hemoglobin level $<11 \mathrm{~g} / \mathrm{dl}$, microcytosis by MCV $<80 \mathrm{fl}$, macrocytosis by $\mathrm{MCV}>98 \mathrm{fl}$, and hypochromic anemia by $\mathrm{MCH}<25 \mathrm{pg}$. ${ }^{[25]}$

\section{Iron parameters}

The quantitative measurement of serum iron, ferritin, and total iron binding capacity (TIBC) was performed on Cobas e411 (Roche Diagnostics International Ltd) according to the manufacturer protocol. Transferrin saturation (TfSat) was calculated as follows: (serum iron/TIBC) $\times 100$.

According to the manufacturer, the normal range of iron was $37-145 \mu \mathrm{g} / \mathrm{dl}$, kit sensitivity was $5 \mu \mathrm{g} / \mathrm{dl}$, and the intra- and inter-assay variations were $<4$ and $6.2 \%$, respectively. The normal range of TIBC was $228-428 \mu \mathrm{g} / \mathrm{dl}$, sensitivity was $16.8 \mu \mathrm{g} / \mathrm{dl}$, and the intra- and inter-assay variations were 1.6 and $2.4 \%$, respectively. The normal range for the ferritin kit was $7-283 \mathrm{ng} / \mathrm{ml}$, sensitivity was $0.5 \mathrm{ng} / \mathrm{ml}$, and the intra- and inter-assay variations were 5.5 and $7.1 \%$, respectively.

\section{Statistical analysis}

Statistical analysis of the results was performed using SPSS version 16 (SPSS Inc., Chicago, USA). Cross-tabulation followed by Chi-square $\left(\chi^{2}\right)$ test was used for frequency analysis. Normality and homogeneity of data were assessed with the Kolmogorov and Smirnoff test and Levene test, respectively. Student's $t$-test or Mann-Whitney test was used to compare two groups based on normality. One-way analysis of variance (ANOVA) followed by least significant difference (LSD) post-hoc test was used to make comparisons between more than two groups. Correlations were determined using Pearson's test. A $p<0.05$ was considered significant.

\section{RESULTS}

\section{Prevalence and types of thyroid disorders and anemia}

Overall, thyroid disorders and anemia were detected in $118(19.6 \%)$ and $123(20.1 \%)$ females, respectively. Anemia was detected in 69 out of 482 participants with normal thyroid profile (14.3\%) and in 52 out 118 females (44\%) with thyroid abnormalities [Table 2]. The prevalence of anemia was statistically different between the control and thyroid disorder groups $(p=0.00002)$.

There was a significant difference $(p=0.01)$ in the mean age between the control ( $33.2 \pm 12.7$ years) and the thyroid dis$\operatorname{order}(29.9 \pm 11.5$ years $)$ groups. The mean age was also significantly lower $(p=0.001)$ for the anemic group $(29.2 \pm 10.3$ years $)$ compared to the non-anemic group $(33.5 \pm 12.9$ years $)$.

The mean \pm standard deviation (SD) of RBC count $\left(4.1 \pm 0.5 \times 10^{6} / \mu \mathrm{l}\right)$, hemoglobin concentration $(11.8 \pm 2.2 \mathrm{~g} /$ $\mathrm{dl}), \mathrm{PCV}(35.8 \pm 5.1 \%)$, and $\mathrm{MCH}(26.1 \pm 3.2 \mathrm{pg})$ were significantly lower in the thyroid disorder group compared to the euthyroid group $(p<0.05)$ [Figure 1]. However, there was no significant difference in MCV between the two groups [Table 3]. Moreover, the median values of serum iron (63.9; range $10.23-180.3 \mu \mathrm{g} / \mathrm{dl})$, ferritin $(44.6 \mathrm{ng} / \mathrm{ml}$; range: $3-199 \mathrm{ng} / \mathrm{ml})$, and TfSat (18.6\%; range: $1-54 \%$ ) were significantly lower and the median TIBC was significantly higher $(407.3 \mu \mathrm{g} / \mathrm{dl}$; range: $237-889 \mu \mathrm{g} / \mathrm{dl})$ in the thyroid disorder group when compared to normal [Figure 2].

The types of thyroid abnormalities detected in the 600 females were as follows: 38 females with overt hypothyroidism (6.3\%), 70 females with subclinical hypothyroidism (11.6\%), and 10 females with overt hyperthyroidism $(1.7 \%)$. Statistical analysis showed that the prevalence of subclinical thyroiditis was significantly higher $(p=0.001)$ compared to the other two types [Table 2].

The types of anemia detected in the study population (600 participants) were microcytic hypochromic anemia in 74 females (12.3\%) and normocytic normochromic anemia in 47 females (7.8\%), and the prevalence of microcytic hypochromic anemia was significantly higher $(p=0.0003)$ compared to the other type [Table 2].

Table 2: Prevalence and types of thyroid disorders and anemia

\begin{tabular}{|c|c|c|c|c|}
\hline & \multirow{2}{*}{$\begin{array}{l}\text { Normal thyroid } \\
(n=482)(\%)\end{array}$} & \multicolumn{3}{|c|}{ Thyroid disorder $(n=118)(\%)$} \\
\hline & & $\begin{array}{l}\text { Overt hypothyroidism } \\
(n=38)\end{array}$ & $\begin{array}{l}\text { Occult hypothyroidism } \\
(n=70)\end{array}$ & $\begin{array}{l}\text { Hyperthyroidism } \\
(n=10)\end{array}$ \\
\hline Non-anemic $(n=479)$ & 413 females (85.7) & 20 females $(52.6)^{*}$ & 36 females $(51.5)^{*}$ & 10 females (100) \\
\hline \multicolumn{5}{|l|}{ Anemic $(n=121)$} \\
\hline Microcytic hypochromic (74 females) & 52 females (10.8) & 8 females $(21)^{*}$ & 14 females $(20)^{*}$ & Zero female $(0)$ \\
\hline Normocytic normochromic (47 females) & 17 females (3.5) & 10 females $(26.4)^{*}$ & 2 females $(28.5)^{*}$ & Zero female $(0)$ \\
\hline
\end{tabular}

$* p<0.05$ compared to normal thyroid 


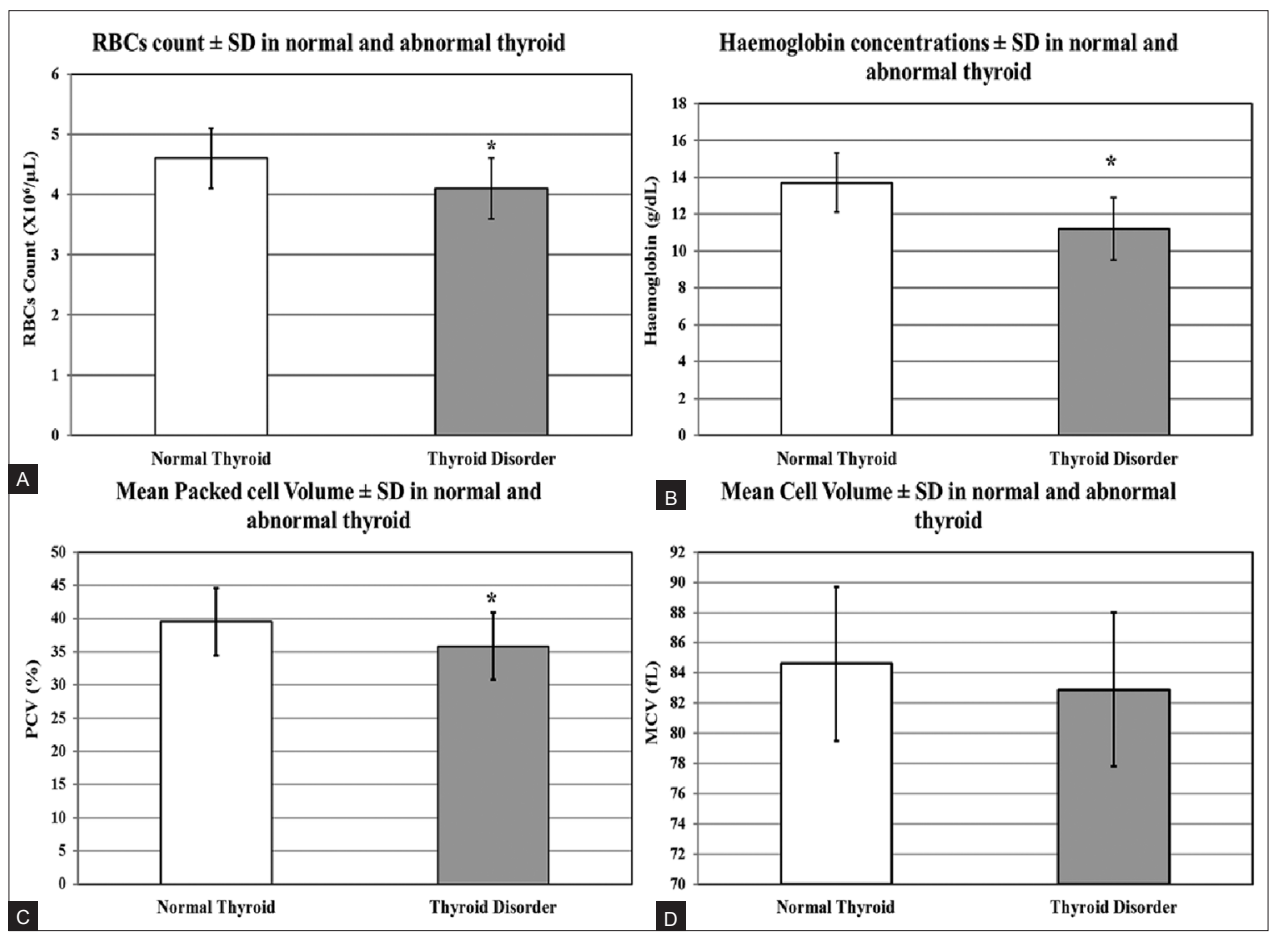

Figure 1: Mean \pm SD of (A) RBC count, (B) hemoglobin concentration, (C) PCV, and (D) MCV in normal and abnormal thyroid (* $p<0.05$ compared to normal thyroid).

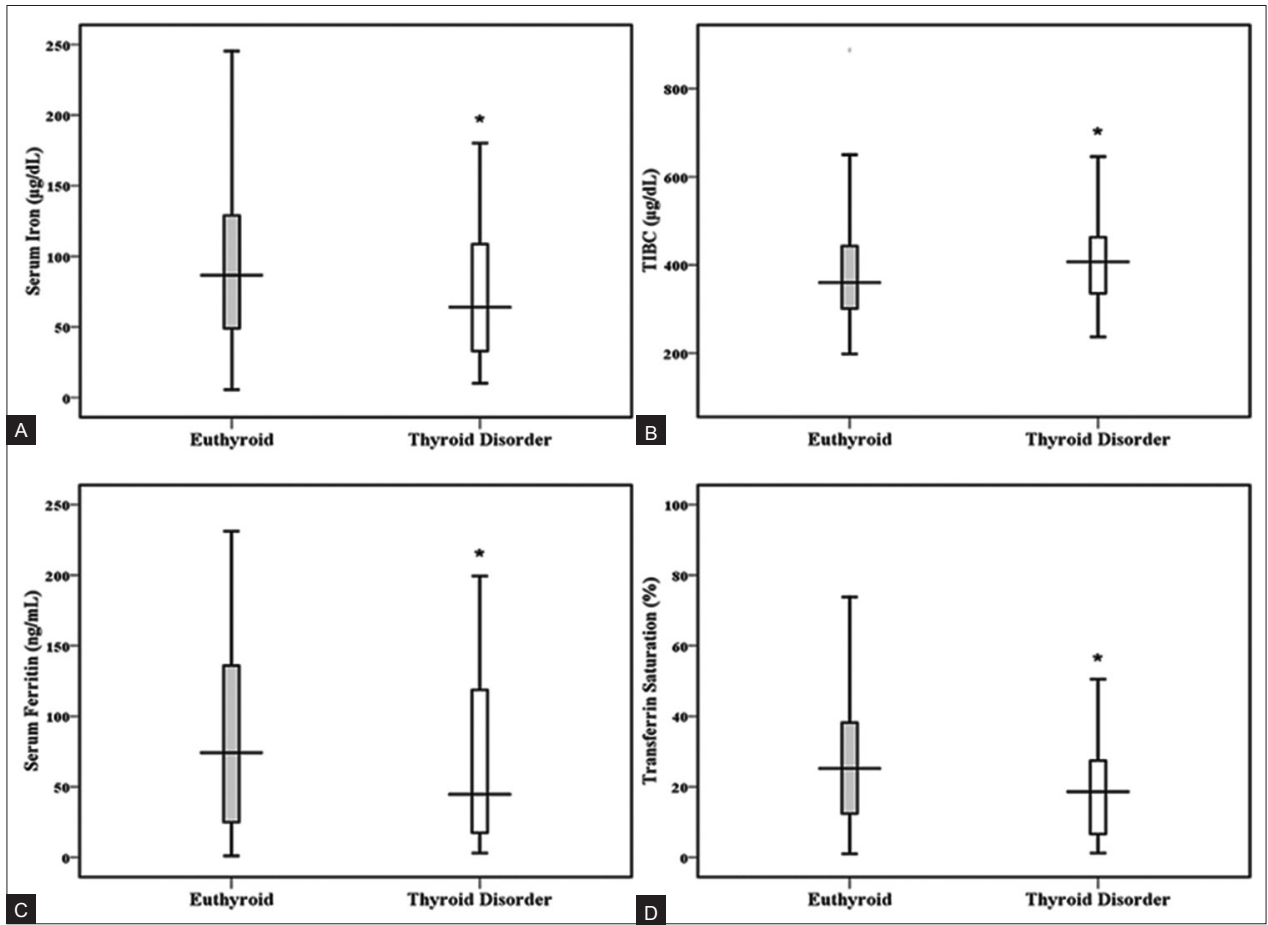

Figure 2: Median of (A) serum iron, (B) TIBC, (C) ferritin, and (D) transferrin saturation in normal and abnormal thyroid (* $p<0.05$ compared to normal thyroid).

\section{Prevalence and types of anemia according to} thyroid profile in all study participants $(N=600)$

Anemia was detected in 69 participants out of 482 with a normal thyroid profile (14.3\%) and the types de- tected were: 52 females with microcytic hypochromic anemia $(10.8 \%)$ and 17 females with normocytic normochromic anemia $(3.5 \%)$. On the other hand, anemia was detected in 52 females out of 118 with abnormal thyroid profile (44\%) and the types detected were: 22 females with microcytic 
Table 3: Mean \pm SD of erythrocyte indices and median of iron parameters

\begin{tabular}{lcccc}
\hline & Normal thyroid & Overt hypothyroidism & Occult hypothyroidism & Hyperthyroidism \\
\hline RBCs count $\left(\times 10^{6} / \mu \mathrm{l}\right)$ & $4.6 \pm 0.5$ & $4 \pm 0.4^{\mathrm{a}}$ & $4.1 \pm 0.5^{\mathrm{a}}$ & $4.6 \pm 0.6^{\mathrm{b}, \mathrm{c}}$ \\
$\mathrm{Hb}(\mathrm{g} / \mathrm{dl})$ & $13.3 \pm 1.8$ & $10.9 \pm 1.7^{\mathrm{a}}$ & $12 \pm 2.3^{\mathrm{a}, \mathrm{b}}$ & $13.7 \pm 1.5^{\mathrm{b}, \mathrm{c}}$ \\
$\mathrm{PCV}(\%)$ & $39.5 \pm 5$ & $33.6 \pm 4^{\mathrm{a}}$ & $36 \pm 4.9^{\mathrm{a}, \mathrm{b}}$ & $40.3 \pm 5.9^{\mathrm{b}, \mathrm{c}}$ \\
$\mathrm{MCV}(\mathrm{fl})$ & $84.6 \pm 6.5$ & $81.1 \pm 8.1$ & $83.3 \pm 7.8$ & $87.1 \pm 4.7^{\mathrm{b}}$ \\
$\mathrm{MCH}(\mathrm{pg})$ & $27.9 \pm 2.7$ & $26.1 \pm 3.4^{\mathrm{a}}$ & $27.3 \pm 3.1$ & $29.2 \pm 1.8^{\mathrm{b}}$ \\
Serum iron $(\mu \mathrm{g} / \mathrm{dl})$ & $86.6($ range: $5.6-245)$ & $42.7(\text { range: } 10.2-163)^{\mathrm{a}}$ & $64.2(\text { range: } 11-180)^{\mathrm{a}, \mathrm{b}}$ & $99.1(\text { range: } 19.5-152)^{\mathrm{b}, \mathrm{c}}$ \\
TIBC $(\mu \mathrm{g} / \mathrm{dl})$ & $360.1($ range: $198.3-889)$ & $412.2(\text { range: } 245-847)^{\mathrm{a}}$ & $411(\text { range: } 237-889)^{\mathrm{a}}$ & $316(\text { range: } 301-589)^{\mathrm{b}, \mathrm{c}}$ \\
Ferritin $(\mathrm{ng} / \mathrm{ml})$ & $74.2($ range: $1.1-231)$ & $49.1(\text { range: } 3-193)^{\mathrm{a}}$ & $43.1(\text { range: } 3.2-199)^{\mathrm{a}}$ & $80.1(\text { range: } 10-150)^{\mathrm{b}, \mathrm{c}}$ \\
Transferrin saturation $(\%)$ & $25.1($ range: $1-50)$ & $9.7(\text { range: } 2-39)^{\mathrm{a}}$ & 21 (range: $1.2-50)^{\mathrm{a}, \mathrm{b}}$ & $31(\text { range: } 3.3-50)^{\mathrm{b}, \mathrm{c}}$ \\
\hline
\end{tabular}

${ }^{\mathrm{a}} p<0.05$ compared to normal thyroid; ${ }^{\mathrm{b}} p<0.05$ compared to primary hypothyroidism; ${ }^{\mathrm{c}} p<0.05$ compared to subclinical hypothyroidism.

Abbreviations: RBC: Red blood cell; PCV: Packed cell volume; MCV: Mean corpuscular volume; MCH: Mean corpuscular hemoglobin; TIBC:

Total iron binding capacity

hypochromic anemia (18.6\%) and 30 females with normocytic normochromic anemia $(25.4 \%)$.

The prevalence of microcytic hypochromic anemia was significantly higher compared to normocytic normochromic anemia within the euthyroid group. Also, both types of anemia were significantly more prevalent in the thyroid disorder group compared to the normal thyroid group [Figure 3]. However, there was no significant difference between both types within the abnormal thyroid group $(p>0.05)$.

Of the 38 females with overt hypothyroidism, anemia was detected in 18 cases (47.4\%) and the types detected were as follows: 8 females with microcytic hypochromic anemia $(21 \%)$ and 10 females with normocytic normochromic anemia (26.4\%). Anemia was detected in 34 out of 70 females with subclinical hypothyroidism (48.5\%) and the types detected were: 14 females with microcytic hypochromic anemia (20\%) and 20 females with normocytic normochromic anemia (28.5\%). There was no significant difference in the prevalence of both types of anemia between the two groups of thyroid insufficiency. Hyperthyroidism was detected in 10 females and anemia was not detected in this group. Significant differences were also detected in the RBC count, hemoglobin concentrations, PCV, TIBC, and TfSat between the different types of thyroid disorders [Table 3].

\section{Prevalence of iron deficiency according to thyroid profile and erythrocyte indices}

Overt iron deficiency (OID; $<37 \mu \mathrm{g} / \mathrm{dl}$ ) was detected in 118 participants $(19.6 \%)$ of the total study population $(N=600)$. The frequency of OID was $17.6 \%(n=85)$ in participants with euthyroid profile $(n=482)$ and $27.9 \%(n=33)$ in women with abnormal thyroid profile $(n=118)$. Statistical analysis revealed that the prevalence of OID was significantly higher in the thyroid disorder group compared with control $(p<0.05)$.

OID was detected in $39.5 \%(n=15 / 38)$ of participants with overt hypothyroidism and $25.7 \%(n=18 / 70)$ of those with occult hypothyroidism. None of the participants with hyperthyroidism had OID. The frequency of OID was significantly higher in both types of hypothyroidism compared with the euthyroid group, and the prevalence was also significantly higher in the "overt hypothyroid" compared with the "occult hypothyroid" group $(p<0.05)$.

According to the state of anemia, OID was detected in $17.9 \%(n=86)$ of the non-anemic group $(n=479)$, $35.1 \%(n=26)$ of the microcytic hypochromic anemia group $(n=74)$, and $12.7 \%(n=6)$ of the normocytic normochromic anemia group $(n=47)$. The prevalence of OID was significantly higher in the microcytic hypochromic anemia group compared with the other two groups $(p<0.05)$. Also, no significant difference was detected between the non-anemic and normocytic normochromic groups $(p>0.05)$.

\section{Prevalence and types of anemia according to thyroid profile in participants with normal serum iron $(n=482)$}

On further analyzing the prevalence of anemia according to thyroid profile in those participants with normal serum iron, anemia was detected in 52 women (13\%) out of 397 with euthyroid profile and the prevalence of microcytic hypochromic anemia $(n=37 ; 9.3 \%)$ was significantly higher compared to normocytic normochromic anemia $(n=15 ; 3.7 \%)(p<0.05)$.

Alternatively, anemia was detected in 37 participants $(43.5 \%)$ out of 85 women with thyroid disorder and the prevalence was significantly higher compared with euthyroid group $(p<0.05)$. However, the frequency of microcytic hypochromic anemia $(n=11 ; 12.9 \%)$ was significantly lower compared with normocytic normochromic anemia $(n=26 ; 30.5 \%)$ within the thyroid disorder group $(p<0.05)$.

Of those women with overt hypothyroidism and normal serum iron $(n=23)$, anemia was detected in 9 cases $(39.1 \%)$; of these, microcytic hypochromic anemia was detected in 2 females $(8.7 \%)$ and normocytic normochromic anemia in 7 women $(30.4 \%)$. Anemia was detected in 28 out of 52 females with occult hypothyroid- 


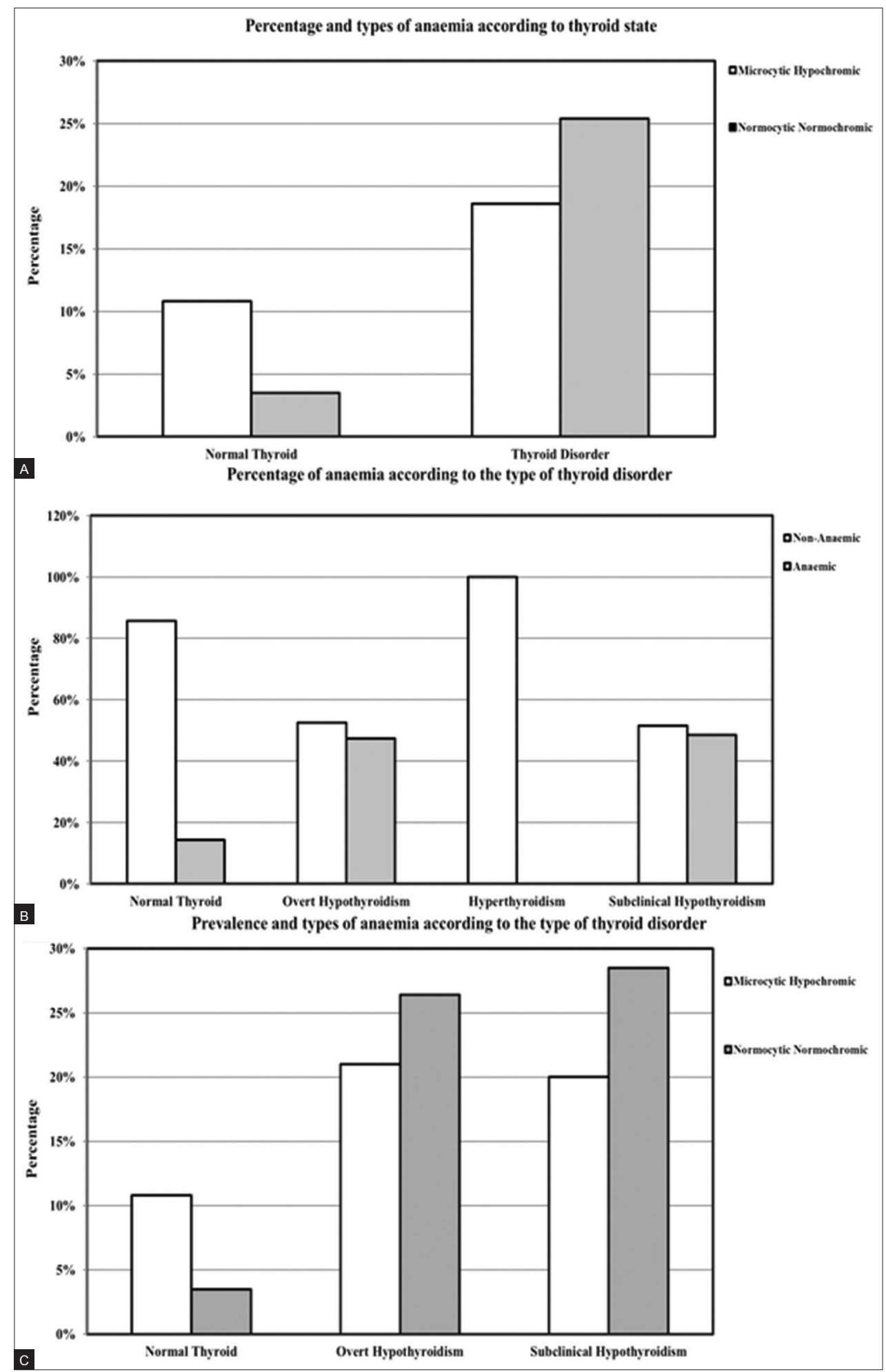

Figure 3: (A) Overall prevalence of anemia in all thyroid groups and (B) prevalence of microcytic hypochromic and (C) normocytic normochromic anemia in the different groups of thyroid disorder found on analyzing the 600 study participants $(* p<0.05$ compared to normal thyroid; hyperthyroidism group is not included as anemia was not detected in any of the cases).

ism (53.8\%) and the types detected were: 9 females with microcytic hypochromic anemia (16.6\%) and 19 females with normocytic normochromic anemia $(36.5 \%)$. The prevalence of normocytic normochromic anemia was significantly higher in the two groups of thyroid insufficiency $(p<0.05)$. 


\section{Correlations between thyroid hormones and erythrocyte indices}

Significant positive correlation was detected between serum FT4 with RBC count, hemoglobin concentrations, and PCV [Figure 4]. Also, TSH correlated positively with TIBC and negatively with serum ferritin [Table 4].

On further analyzing the correlation of thyroid hormones with erythrocyte indices in those participants with normal serum iron $(n=482)$, significant correlations were detected for serum FT4 and TSH with RBC count, hemoglobin concentrations, and PCV [Table 5].

\section{DISCUSSION}

Thyroid disorders-induced anemia is a common health problem and achieving a euthyroid state would correct the associated hematological abnormalities. ${ }^{[14,20-22]}$ To the best of our knowledge, this is the first study to report the prevalence of thyroiditis-induced anemia in non-pregnant females during the childbearing age in Saudi Arabia.

The present study showed thyroid abnormalities in $19.6 \%$ of the study population and the most common thyroid disorders were subclinical hypothyroidism followed by overt hypothyroidism. A significant increase was observed in the prevalence of anemia in females with thyroid disorders and it was associated with a decrease in the number of RBCs, hemoglobin concentration, $\mathrm{PCV}$, and $\mathrm{MCH}$. Moreover, OID was significantly more prevalent in the thyroid disorder group compared with the euthyroid group, and it was associated with a significant increase in TIBC and a significant decrease in serum iron, ferritin, and TfSat. The types of anemia detected in the present study were microcytic hypochromic and normocytic normochromic anemia. The prevalence of


Figure 4: Correlation of serum free T4 with (A) RBC count, (B) hemoglobin concentration, (C) packed cell volume, and (D) correlation of serum TSH with serum transferrin saturation.

Table 4: Results of correlation analysis using Pearson's test for the hematological indices and iron parameters with TSH and FT4 levels in all study participants $(N=600)$

\begin{tabular}{cccccccccc}
\hline & RBCs & $\mathrm{Hb}$ & $\mathrm{HCT}$ & $\mathrm{MCV}$ & $\mathrm{MCH}$ & Iron & TIBC & Ferritin & Transferrin saturation \\
\hline TSH & & & & & & & & & \\
$r$ value & $-0.288^{*}$ & $-0.291^{*}$ & $-0.295^{*}$ & $-0.134^{*}$ & $-0.143^{*}$ & $-0.161^{*}$ & $-0.136^{*}$ & -0.048 & $-0.184^{*}$ \\
$\quad p$ value & $0.03 \times 10^{-9}$ & $0.006 \times 10^{-11}$ & $0.01 \times 10^{-14}$ & 0.001 & 0.00004 & 0.0007 & 0.001 & 0.244 & 0.00005 \\
FT4 & & & & & & & & \\
$r$ value & $0.443^{*}$ & $0.474^{*}$ & $0.390^{*}$ & $0.182^{*}$ & $0.260^{*}$ & $0.107^{*}$ & -0.053 & 0.013 & $0.123^{*}$ \\
$p$ value & $0.02 \times 10^{-16}$ & $0.04 \times 10^{-20}$ & $0.02 \times 10^{-18}$ & 0.000007 & $0.01 \times 10^{-5}$ & 0.008 & 0.1 & 0.7 & 0.003
\end{tabular}

${ }^{*} p<0.01$. Abbreviations: RBC: Red blood cell; MCV: Mean corpuscular volume; MCH: Mean corpuscular hemoglobin; TIBC: Total iron binding capacity; FT: free thyroxin hormone; TSH: Thyroid stimulating hormone; HCT: Hematocrit 
Table 5: Results of correlation analysis using Pearson's test for the hematological indices and iron parameters with TSH and FT4 in participants with normal serum iron level $(N=482)$

\begin{tabular}{cccccccccc}
\hline & $\begin{array}{c}\text { Red blood } \\
\text { cell count }\end{array}$ & Hemoglobin & Hematocrit & $\begin{array}{c}\text { Mean corpuscular } \\
\text { volume }\end{array}$ & $\begin{array}{c}\text { Mean corpuscular } \\
\text { hemoglobin }\end{array}$ & Iron & $\begin{array}{c}\text { Total iron } \\
\text { binding capacity }\end{array}$ & $\begin{array}{c}\text { Ferritin } \\
\text { Transferrin } \\
\text { saturation }\end{array}$ \\
\hline TSH & & & & & & & & & \\
$r$ value & $-0.271^{*}$ & $-0.250^{*}$ & $-0.298^{*}$ & -0.049 & -0.038 & $-0.151^{*}$ & $0.163^{*}$ & -0.009 & $-0.182^{*}$ \\
$\quad p$ value & $0.01 \times 10^{-7}$ & $0.02 \times 10^{-6}$ & $0.02 \times 10^{-9}$ & 0.2 & 0.4 & 0.001 & 0.0003 & 0.8 & 0.00006 \\
FT4 & & & & & & & & \\
$r$ value & $0.446^{*}$ & $0.452^{*}$ & $0.371^{*}$ & $0.106^{*}$ & $0.186^{*}$ & 0.075 & $-0.104^{*}$ & -0.015 & $0.102^{*}$ \\
$p$ value & $0.005 \times 10^{-21}$ & $0.01 \times 10^{-22}$ & $0.03 \times 10^{-15}$ & 0.02 & 0.0004 & 0.09 & 0.02 & 0.7 & 0.02 \\
\hline
\end{tabular}

${ }^{*} p<0.01$. Abbreviations: TSH: Thyroid stimulating hormone; FT: Free thyroxin hormone

both types significantly increased in overt and occult hypothyroidism compared to the euthyroid group. Furthermore, serum FT4 correlated significantly with RBC count, hemoglobin concentration, PCV, and $\mathrm{MCH}$. On the other hand, TSH correlated significantly but weakly with serum iron, TIBC, and TfSat.

The results of the present study suggest that thyroid disorders are common in non-pregnant females of childbearing age from the Western province of the kingdom. Also, the prevalence of anemia and iron deficiency was significantly higher in women with hypothyroidism. The significant correlations of FT4 and TSH with erythrocyte indices and iron parameters suggest that both hormones could have a role in the regulation of erythropoiesis and iron metabolism.

Thyroid disorders are a major health problem worldwide, affect females more than males, and the prevalence varies in different societies. ${ }^{[2-5]}$ Hypothyroidism, either in overt or occult form, is the most common type with a prevalence of up to $20 \%$ in the elderly population..$^{[6-9,13]}$ Despite the fact that thyroid disorders are frequently encountered in Saudi Arabia, these conditions are understudied and there is a lack of information on their prevalence, types, and etiological factors contributing to their development. ${ }^{[26,27]}$

The findings of the present study agree with the previous findings and show that the overall prevalence of thyroid disorders was $19.6 \%$, suggesting that thyroid dysfunction is a common endocrine disorder in non-pregnant Saudi females, at least in the Western province of the kingdom. The majority of cases had subclinical hypothyroidism (11.6\%) followed by primary hypothyroidism (6.3\%), and hyperthyroidism (1.7\%) was the least frequent type. However, future studies should include the thyroid antibodies profile, free $\mathrm{T} 3$, and urine iodine to precisely determine the type and etiology of thyroid disorder in the kingdom.

Thyroid diseases affect the process of hematopoiesis and several previous reports have shown an association between the different types of thyroid disease and hematological abnormalities. The most prevalent hematological disorder with thyroiditis is anemia and it is indicated by a decrease in the number of RBCs and hemoglobin concentration. ${ }^{[8,11,13,16,19]}$ The present report correlates with the afore- mentioned findings as a significant decrease was observed in the number of RBCs, hemoglobin concentration, PCV, and $\mathrm{MCH}$ between the thyroid disorder and normal thyroid groups and the prevalence of anemia increased by threefold with thyroid dysfunction compared with euthyroid females.

Although anemia was reported with different types of thyroiditis, it is more common in hypothyroidism compared to hyperthyroidism. ${ }^{[3,7,8,11,14,16]}$ The decreased prevalence of anemia with hyperthyroidism could be explained by the observed increase in erythrocytosis. ${ }^{[8,16]}$ The current study supports the earlier observations as it showed a significant increase in the prevalence of anemia in the overt and occult hypothyroidism groups compared to normal thyroid group. Also, all the detected cases of hyperthyroidism $(n=10)$ had normal erythrocyte indices and iron parameters. This is further supported by the significant correlation found between thyroid hormones with erythrocyte and iron indices.

Several forms of anemia have been reported with thyroid disorders and they include normocytic normochromic, microcytic and/or macrocytic hypochromic, and the severity of anemia is related to the degree of thyroid abnormality. ${ }^{[21,22]}$ Anemia of chronic disease, which is in the form of normocytic normochromic anemia, is the most frequently encountered type of anemia in hypothyroidism. ${ }^{[8,16]}$ It has been suggested that thyroid hormone deficiency may lead to bone marrow repression and/or decrease in erythropoietin production due to the reduction of $\mathrm{O}_{2}$ requirements. ${ }^{[20]} \mathrm{Hypo}-$ chromic microcytic anemia is less frequently associated with hypothyroidism and it is mainly due to iron deficiency. ${ }^{[20-22]}$

The results of the present study are in agreement with the previous reports as normocytic normochromic anemia and microcytic hypochromic anemia were the only two types of anemia detected. The frequency of both types was significantly higher in hypothyroidism compared to normal thyroid group. However, there was no significant difference in the prevalence of both types either between overt and occult hypothyroidism or within each subtype of thyroid insufficiency on analyzing the results generated from 600 participants.

Interestingly, the exclusion of women with OID in further analysis revealed that the most common type of anemia 
associated with both overt and occult hypothyroidism was normocytic normochromic anemia and, similar to previous studies, its prevalence was significantly higher compared with microcytic hypochromic anemia. Hence, future studies should rule out the possibility of hemolysis as a cause of normocytic normochromic anemia, despite the fact that hemolytic anemia is rare in hypothyroidism. ${ }^{[8,12,16]} \mathrm{Also}$, the observed cases of microcytic hypochromic anemia in the subanalysis of participants with normal serum iron level could be due to the co-existence of a chronic inflammation (e.g. autoimmune thyroiditis). Therefore, future studies should measure the different thyroid autoantibodies and include the measurement of serum proinflammatory cytokines.

Several studies investigated the correlation between thyroid hormones and erythrocyte indices. Bremner et al. have shown significant correlation between free $\mathrm{T} 4$ and $\mathrm{TSH}$ levels and hemoglobin concentrations in 1011 euthyroid subjects. They, therefore, concluded that small differences in thyroid hormones in euthyroid subjects are associated with significant alteration in erythrocyte. ${ }^{[28]}$ Another recent study by Schindhelm et al. reported similar results in 701 euthyroid subjects. However, the authors did not observe any correlation between TSH and erythrocyte indices. ${ }^{[29]}$ The present study agrees with the reported findings of Bremner et al. as there was a significant decrease in erythrocyte indices in the abnormal thyroid group compared to control and there was a significant positive correlation of serum FT4 with the RBC count, hemoglobin concentrations, PCV, and $\mathrm{MCH}$. The present findings support the hypothesis that FT4 plays an important role in the regulation of erythropoiesis.

Also, the observed significant decrease in the iron parameters and increase in the prevalence of OID within the hypothyroidism groups suggests that thyroid deficiency, either in the overt or occult form, could affect the metabolism of iron. It appears from the results of previous reports that both iron metabolism and thyroid functions are interdependent and each one of them could have a regulatory role on the other. For instance, decrease in serum iron levels has been observed in patients with subclinical hypothyroidism. ${ }^{[28]}$ Moreover, subclinical hypothyroidism was investigated in iron-deficient patients and those who did not respond to iron salt alone and interestingly, the combination of levothyroxine and iron salt has shown a better performance compared to each treatment alone. ${ }^{[30]}$ Thyroid hormones were also shown to regulate the gene expression of transferrin; hence, it has been suggested that the thyroid hormones regulate the iron metabolism. ${ }^{[29-32]}$

On the other hand, several other studies have demonstrated that iron deficiency could be a risk factor for the development of thyroid abnormalities. A recent experimental study reported that iron deficiency prior to pregnancy in female rats led to maternal hypothyroxinemia during gestation. ${ }^{[33]}$ Iron supplementation to children with euthyroid goiter was also shown to reduce the size of goiter in a randomized controlled study. ${ }^{[34]}$ Also, mild thyroid hormone insufficiency was reported in cases of fetal and neonatal iron deficiency, ${ }^{[35]}$ and iron deficiency was also more common in euthyroid subjects and in those who were positive for several thyroid autoantibodies. ${ }^{[36]}$

The results of the present study support the assumption that both thyroid dysfunction and serum iron are symbiotic, as suggested by the observed significant increase in the prevalence of iron deficiency in the thyroid disorder group. This is additionally supported by the current observation of significant correlations of serum TSH positively with TIBC and negatively with serum iron and TfSat. However, mechanistic elucidation for the observed relation between serum iron and thyroid dysfunction is not possible from the present data. Therefore, future studies should investigate possible common molecules that could be involved in the regulation of thyroid and iron metabolism. Hepcidin could be a potential interesting molecule as it is the main iron regulatory hormone and also strongly involved in the regulation of immune system. ${ }^{[37,38]}$ Hence, it could be hypothesized that pathological alteration in the activity of hepcidin could result in iron deficiency and/or thyroid dysfunction. However, further studies are required to explore the previous hypothesis.

In conclusion, thyroid disorders are common in non-pregnant Saudi females in the Western province of the kingdom and they are associated with a d ecrease in RBC count, hemoglobin concentration, hematocrit value, and iron parameters, and with anemia in $44 \%$ of cases. Normocytic normochromic anemia and microcytic hypochromic anemia were the most prevalent types associated with thyroid dysfunction. Further studies are needed to identify the underlying mechanism (s) and the etiological factors contributing to the development of thyroiditis-induced anemia and to study the effects of thyroid hormones on iron metabolism.

\section{Acknowledgment}

The author would like to thank Ms. Athar Khojah and Ms. Bashayer Al-Barakati from the Laboratory Medicine Department, Faculty of Applied Medical Sciences, Umm Al-Qura University for processing the samples.

\section{REFERENCES}

1. Franchini M, Montagnana M, Manzato F, Vescovi PP. Thyroid dysfunction and hemostasis: An issue still unresolved. Semin Thromb Hemost 2009;35:288-94.

2. Yen PM. Physiological and molecular basis of thyroid hormone action. Physiol Rev 2001;81:1097-142.

3. Vanderpump M. Thyroid autoimmunity following an iodization programme. Clin Endocrinol (Oxf) 2011;75:10-1. 
4. Col NF, Surks MI, Daniels GH. Subclinical thyroid disease: Clinical applications. JAMA 2004;291:239-43.

5. Surks MI, Ortiz E, Daniels GH, Sawin CT, Col NF, Cobin RH, et al. Subclinical thyroid disease: Scientific review and guidelines for diagnosis and management. JAMA 2004;291:228-38.

6. Wilson GR, Curry RW Jr. Subclinical thyroid disease. Am Fam Physician 2005;72:1517-24.

7. Vanderpump MP. The epidemiology of thyroid disease. Br Med Bull 2011;99:39-51.

8. Erdogan M, Kosenli A, Ganidagli S, Kulaksizoglu M. Characteristics of anemia in subclinical and overt hypothyroid patients. Endocr J 2012;59:213-20.

9. Khandelwal D, Tandon N. Overt and subclinical hypothyroidism: Who to treat and how. Drugs 2012;72:17-33.

10. Bagchi N, Brown TR, Parish RF. Thyroid dysfunction in adults over age 55 years. A study in an urban US community. Arch Intern Med 1990;150:785-7.

11. Fein HG, Rivlin RS, Anemia in thyroid diseases. Med Clin North Am 1975;59:1133-45.

12. Iddah MA, Macharia BN. Autoimmune thyroid disorders. ISRN Endocrinol 2013;2013:509764.

13. Omar S, Hadj Taeib S, Kanoun F, Hammami MB, Kamoun S, Ben Romdhane N, et al. Erythrocyte abnormalities in thyroid dysfunction. Tunis Med 2010;88:783-8.

14. Perlman JA, Sternthal PM: Effect of 131I on the anemia of hyperthyroidism. J Chronic Dis 1983;36:405-12.

15. Lima CS, Zantut Wittmann DE, Castro V, Tambascia MA, Lorand-Metze I, Saad ST, et al. Pancytopenia in untreated patients with Graves' disease. Thyroid 2006;16:403-9.

16. Iddah MA, Macharia BN, Ng'wena AG, Keter A, Ofulla AV. Thryroid hormones and hematological indices levels in thyroid disorders patients at moi teaching and referral hospital, Western kenya. ISRN Endocrinol 2013;2013:385940.

17. Montagnana M, Lippi G, Targher G, Salvagno GL, Guidi GC. The red blood cell distribution width is associated with serum levels of thyroid stimulating hormone in the general population. Int $\mathrm{J}$ Lab Hematol 2009;31:581-2.

18. Grymula K, Paczkowska E, Dziedziejko V, Baskiewicz-Masiuk M, Kawa M, Baumert B, et al. The influence of 3,3',5-triiodo-L-thyronine on human haematopoiesis. Cell Prolif 2007;40:302-15.

19. Horton L, Coburn RJ, England JM, Himsworth RL. The haematology of hypothyroidism. Q J Med 1976;45:101-23.

20. Christ-Crain M, Meier C, Huber P, Zulewski H, Staub JJ, Muller B. Effect of restoration of euthyroidism on peripheral blood cells and erythropoietin in women with subclinical hypothyroidism. Hormones (Athens) 2003;2:237-42.

21. Cinemre H, Bilir C, Gokosmanoglu F, Bahcebasi T. Hematologic effects of levothyroxine in iron-deficient subclinical hypothyroid patients: A randomized, double-blind, controlled study. J Clin Endocrinol Metab 2009;94:151-6.

22. Bashir H, Bhat MH, Farooq R, Majid S, Shoib S, Hamid R, et al. Comparison of hematological parameters in untreated and treated subclinical hypothyroidism and primary hypothyroidism patients. Med J Islam Repub Iran 2012;26:172-8.
23. Sahin M, Toprak SK, Altintas ND. Should women with abnormal serum thyroid stimulating hormone undergo screening for anemia? Arch Pathol Lab Med 2009;133:1188.

24. Baloch Z, Carayon P, Conte-Devolx B, Demers LM, Feldt-Rasmussen U, Henry JF, et al. Laboratory medicine practice guidelines. Laboratory support for the diagnosis and monitoring of thyroid disease. Thyroid 2003;13:3-126.

25. Rasheed P, Koura MR, Al-Dabal BK, Makki SM. Anemia in pregnancy: A study among attendees of primary health care centers. Ann Saudi Med 2008;28:449-52.

26. Akbar DH, Ahmed MM, Al-Mughales J. Thyroid dysfunction and thyroid autoimmunity in Saudi type 2 diabetics. Acta Diabetol 2006;43:14-8.

27. Aljohani NJ,Al-Daghri NM, Al-Attas OS, Alokail MS, Alkhrafy KM, Al-Othman A, et al. Differences and associations of metabolic and vitamin D status among patients with and without sub-clinical hypothyroid dysfunction. BMC Endocr Disord 2013;13:31.

28. Bremner AP, Feddema P, Joske DJ, Leedman PJ, O'Leary PC, Olynyk JK, et al. Significant association between thyroid hormones and erythrocyte indices in euthyroid subjects. Clin Endocrinol (Oxf) 2012;76:304-11.

29. Schindhelm RK, ten Boekel E, Heima NE, van Schoor NM, Simsek S. Thyroid hormones and erythrocyte indices in a cohort of euthyroid older subjects. Eur J Intern Med 2013;24:241-4.

30. Ravanbod M, Asadipooya K, Kalantarhormozi M, Nabipour I, Omrani GR. Treatment of iron-deficiency anemia in patients with subclinical hypothyroidism. Am J Med 2013;126:420-4.

31. Das C, Sahana PK, Sengupta N, Giri D, Roy M, Mukhopadhyay P. Etiology of anemia in primary hypothyroid subjects in a tertiary care center in Eastern India. Indian J Endocrinol Metab 2012;16:S361-3.

32. Huang YH, Tsai MM, Lin KH. Thyroid hormone dependent regulation of target genes and their physiological significance. Chang Gung Med J 2008;31:325-34.

33. Hu X, Teng X, Zheng H, Shan Z, Li J, Jin T, et al. Iron deficiency without anemia causes maternal hypothyroxinemia in pregnant rats. Nutr Res 2014;34:604-12.

34. Ordooei M, Akbarzadeh M, Soleimanizad R, Shamsi F, Masoumi Dehshiri R. The effect of iron supplement on children with euthyroid goiter: A randomized placebo-controlled clinical trial. Iran J Ped Hematol Oncol 2014;4:84-8.

35. Bastian TW, Prohaska JR, Georgieff MK, Anderson GW. Fetal and neonatal iron deficiency exacerbates mild thyroid hormone insufficiency effects on male thyroid hormone levels and brain thyroid hormone-responsive gene expression. Endocrinology 2014;155:1157-67.

36. Wang YP, Lin HP, Chen HM, Kuo YS, Lang MJ, Sun A. Hemoglobin, iron, and vitamin B12 deficiencies and high blood homocysteine levels in patients with anti-thyroid autoantibodies. J Formos Med Assoc 2014;113:155-60.

37. Ruchala P, Nemeth E. The pathophysiology and pharmacology of hepcidin. Trends Pharmacol Sci 2014;35:155-61.

38. Song SN, Iwahashi M, Tomosugi N, Uno K, Yamana J, Yamana S, et al. Comparative evaluation of the effects of treatment with tocilizumab and TNF-alpha inhibitors on serum hepcidin, anemia response and disease activity in rheumatoid arthritis patients. Arthritis Res Ther 2013;15:R141 